\title{
Design a new wire cut EDM machine for turning operation
}

\author{
Harshadkumar Patel $^{1^{*}}$ and Dhaval M. Patel ${ }^{2}$ \\ Research Scholar, Ganpat University, Gujarat, India ${ }^{1}$ \\ Professor, Vishwakarma Government Engineering College, Gujarat, India ${ }^{2}$
}

Received: 10-March-2019; Revised: 20-April-2019; Accepted: 24-April-2019

(C)2019 Harshadkumar Patel and Dhaval M. Patel. This is an open access article distributed under the Creative Commons Attribution (CC BY) License, which permits unrestricted use, distribution, and reproduction in any medium, provided the original work is properly cited.

\begin{abstract}
Advanced and complex materials machining are the biggest problem in present industries. Advanced and complex materials used in different application like super alloys, tool, steels, ceramics, and composites with the need of high accuracy and good surface finishing. Its material very harder, so material removal is very harsh. This challenge can be solved by unconventional machining processes. The unconventional machining machine is machining the material to achieve high accuracy, reduce the material removal time and respectable surface finishing on the surface of the material. Wire cut electrical discharge machining (WEDM) is less used in turning operation in now a day. So, in this research, design and develop a new turning WEDM machine. In developed turning WEDM, different parameters effect on machining on turning operations. So, some parameters are investigated in this research. Experiments investigate the effect of varying peak current, infeed and revolution per minute of spindle on GCr15 material to examine the influence on the material removal rate (MRR) using ANOVA analysis. In the experiment, L27 orthogonal array is chosen for full factorial design of experiment (DOE) to manner analysis. The ANOVA calculation by both mathematical steps and design expert software. The Experimental outcome shows that the maximum material removal rate is $4.2 \mathrm{~mm}^{3} / \mathrm{min}$ at $90 \mu m$ rotational infeed.
\end{abstract}

\section{Keywords}

CWEDM, ANOVA, MRR, Mathematical modelling, Turning operation.

\section{Introduction}

Wire cut electrical discharge machining (WEDM) is popular in manufacturing industries for profile cutting of harder or complex material or parts. Its thermal erosion machining process capable of harder and complex parts with higher accuracy. In WEDM removed material by applying spark heat and erosion system. WEDM is an unconventional machining process using thermal and electrical power which erodes the material from harder components by creating an ionized column between components and electrode, whole affected area sinks in liquid electrical fluid as shown in Figure 1 [1]. Now days, the WEDM research area is wider. Several researchers have used WEDM in hybrid material removal mechanism. WEDM also used for cylindrical material removal. $\mathrm{Qu}$ et al. [2, 3] introduce a design of an accurate, springy and corrosion protected underwater rotary spindle. This error analysis done by frequency spectrum and found a major source of error is frequency spectrum.

\footnotetext{
*Author for correspondence
}

Researchers gain maximum material removal rate (MRR) is $69.6 \mathrm{~mm}^{3} / \mathrm{min}$ for brass material and 20.9 $\mathrm{mm}^{3} / \mathrm{min}$ for Carbide material. Balamurli et al. [4] worked on wire cut electrical discharge machine for cylindrical parts development and study different effects on material removal rate and surface finishing. Research is found max MRR $2.87 \mathrm{~mm}^{3} / \mathrm{min}$ for SS316 Material. Also found MRR is most significantly influenced by rotational speed with a maximum value of MRR as $2.189 \mathrm{~mm}^{3} / \mathrm{min}$ at 500 RPM.

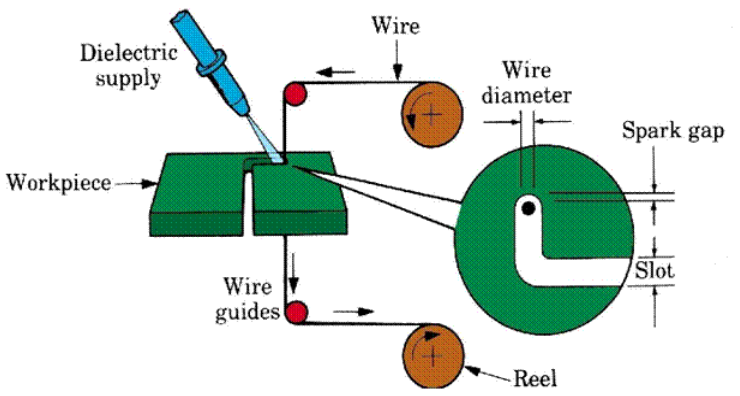

Figure 1 Schematic representation of WEDM cutting process 
Baki et al. [5] also develop rotary setup and give optimal combination process variable obtained from the proposed methods is the set with spindle speed-

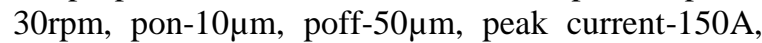
wire feed $-3 \mathrm{~mm} / \mathrm{min}$ and servo- $90 \mathrm{~V}$. An experiment is found max MRR $9.756 \mathrm{~mm}^{3} / \mathrm{min}$ for Ti-6Al-4V material. Haddad et al. [6] also develop rotary setup and show that design of experiment (DOE) useful for experiment. An experiment is found max MRR 13.04 $\mathrm{mm}^{3} / \mathrm{min}$ for D3 Steel Material. Mohammadi et al. [7] introduced the design of a precise, flexible and corrosion-resistant rotary spindle submerged. An experiment is found maximum MRR is 63.799 $\mathrm{mm}^{3} / \mathrm{min}$ for cemented steel. Haddad and Tehrani [8] also design rotary setup and found maximum MRR is $14.92 \mathrm{~mm}^{3} / \mathrm{min}$ for D3 Steel. Zhu et al. [9] also develop rotary setup and found maximum MRR is $3.09 \mathrm{~mm}^{3} / \mathrm{min}$ for GCr15 Material. Mohammadi et al. [10] gives the ultrasonic vibration effects on wire in wire electrical discharge turning machine on complex machining material. Research also shows the machining parameters performance and accomplish the maximum material removal rate was $2.08026 \mathrm{~mm}^{3} / \mathrm{min}$. Janardhan and Samuel [11] developed an economical and a modest rotary spindle for turning a component in WEDM. The experiment was found maximum MRR is $9.75 \mathrm{~mm}^{3} / \mathrm{min}$ for Brass Material. Gong et al. [12] to develop low speed wire electrical discharge turning. This research work study on effect of surface roughness.

Chen et al. [13] developed a new type rotary spindle have different capabilities in cylindrical machining like rough, semi-finish, and finish machining. They also studied the two parameters, material removal rate and surface roughness. The experiment was found the maximum MRR is $4.79965 \mathrm{x} 105 \mu \mathrm{m}^{3} / \mathrm{min}$ for cemented carbide k15 material. Krishnan and Samuel [14] discussed in the research on material removal model for improving the productivities. They introduced the adaptive neuro-fuzzy inference system for artificial neural network with feedforward back-propagation algorithm for finest modelling. The experiment was found maximum MRR is $3.78 \mathrm{~mm}^{3} / \mathrm{min}$. Mohammadi et al. [15] used the ultrasonic vibration in cylindrical parts machining in WEDM. The experiment result shows the combined effects are most significant in turning the material. Experimental setup is truthful, flexible, carrion protected and capable to work under dielectric fluid. Experimental results were also found maximum MRR is $3.03 \mathrm{~mm}^{3} / \mathrm{min}$ for HSS material. Parthiban et al. [16] developed a rotary spindle unit and found maximum MRR is $4.52 \mathrm{~mm}^{3} / \mathrm{min}$ for tungsten carbide. Zhu et al. [17] developed the rotary setup large aspect-ratio rotational parts machining in WEDM. The setup worked under two stages, polygon sectional feeding strategy and final rapid contouring method and find faster material removal on components. They found maximum MRR is 26.25 $\mathrm{mm}^{3} / \mathrm{min}$ for nickel based elastic alloy $3 \mathrm{~J} 40$ material.

\section{Design of cylindrical wire cut EDM}

In this research all the calculative design and modelling have been done. This machine basically divided into five divisions likes, wire feed mechanism, CNC table, pulse generator, control system and workpiece holding device.

The calculative design and modelling are shown in Figure 2 and Figure 3. Workpiece holding device rotates the workpiece as per control signal. Workpiece holding device modelling and development is shown in Figure 4 and Figure 5.

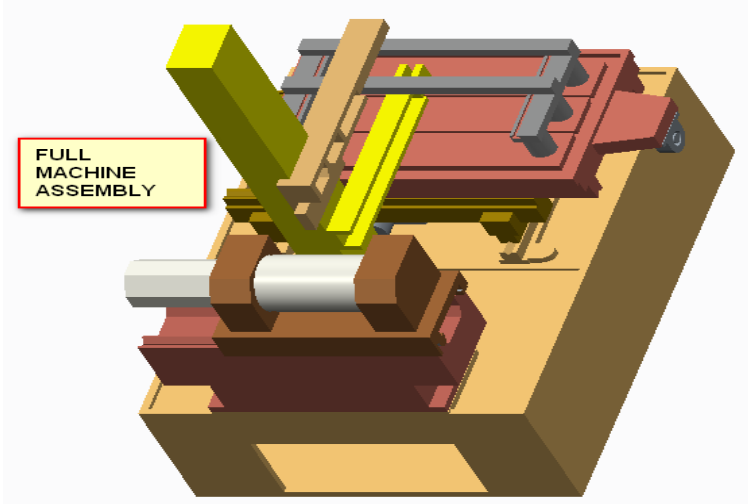

Figure 2 Modelling of new cylindrical wire cut EDM 


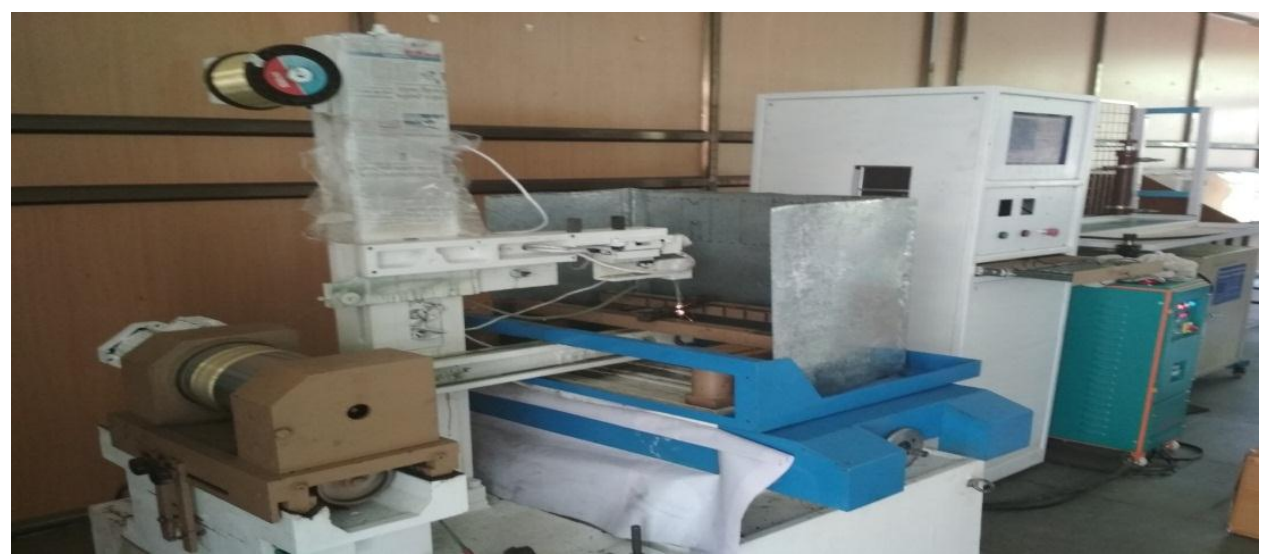

Figure 3 Development of new cylindrical wire cut EDM

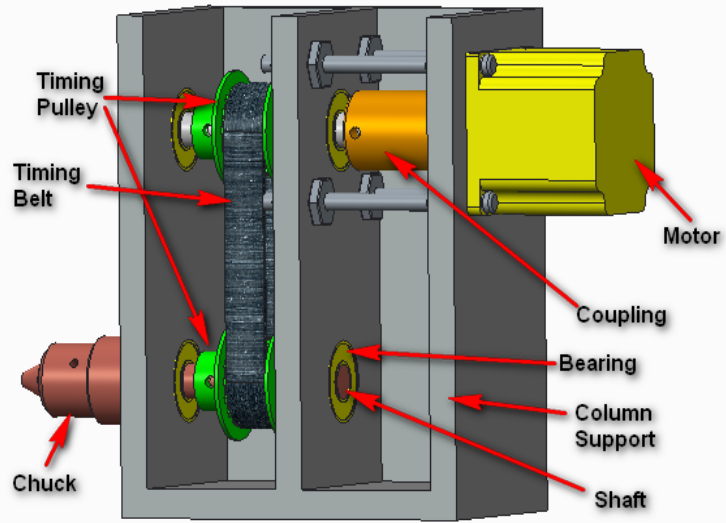

Figure 4 Modelling of the cylindrical workpiece holding device

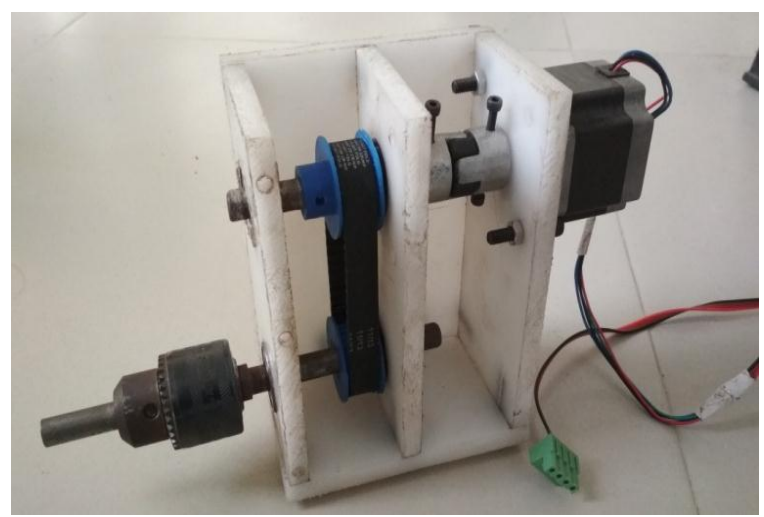

Figure 5 Development of new workpiece holding device

\section{Experimental planning}

\subsection{Material specification}

Wire-cut EDM is ordinarily utilized when low remaining anxieties are wanted, on the grounds that it doesn't require high cutting powers for expulsion of material.
Table 1 Material specification: GCr15

\begin{tabular}{lll}
\hline Chemical & $\begin{array}{l}\text { Obtained } \\
(\boldsymbol{\%})\end{array}$ & $\begin{array}{l}\text { value } \\
\text { Required } \\
\text { value }\end{array}$ \\
\hline Carbon & 0.98 & $0.95-1.10$ \\
Silicon & 0.25 & $0.15-0.35$ \\
Manganese & 0.30 & $0.20-0.40$ \\
Chromium & 1.50 & $1.35-1.60$ \\
Molybdenum & 0.09 & Max 0.10 \\
Phosphorus & 0.021 & Max 0.025 \\
Sulfur & 0.10 & Max 0.10 \\
\hline
\end{tabular}

GCr15 is a bearing steel. This can be utilized in the toughened condition. GCr15 offers high consumption obstruction, wear quality and high hardness. The GCr15 material tested in Divine Laboratories, Ahmedabad for chemical composition as shown in Table 1.

GCr15 Material generally used in higher toughness requirements like gear box of the supercharger, rear axle, greatly clip of spring load, pipe joining in oil industries and different cutting finish tools etc.

Researchers after a long work in wire electrical discharge machine have find notorious two types machining parameters, electrical factors (ON, OFF, peak current (IP), the spark voltage (SV)) and nonelectrical factor (wire tension, wire speed, dielectric pressure) was critically affected on output performance parameters of machining. Material thicknesses have little effect on MRR and spindle rotation (SR as RPM) as it remains constant by varying parameter this carrying on literature review. On WEDM main problem in selection of the level depends on wire breakage.

Few parameters are taken as a varying parameter while some kept as constant as per the shop floor engineer's opinion and based on referring machine operating manual and literature survey. Wire 
consumption is the dominant issue. By keeping constant feed rate and peak current in this research work the varying parameter effect should be checked. Fixed parameter values are set based on trial run experiments. Fixed parameters set at values which remain constant throughout all experiments. Though these parameters can vary, but here it kept constant and then check the effect of control parameters. The reason to make a parameter constant based in the study of the operator setting phenomenon. Table 2 shows the fixed parameters.

Table 2 Fixed parameters

\begin{tabular}{ll}
\hline Fixed parameter & Set value \\
\hline Wire material & Brass
\end{tabular}

\begin{tabular}{ll}
\hline Fixed parameter & Set value \\
\hline Peak current (IP) & 1 \\
Pulse peak voltage & 8 \\
Servo feed setting & 2100 \\
\hline
\end{tabular}

3.2Input parameters and their levels

$>$ A level 3 factor design was developed by using full factorial method.

$>$ Design expert software has been used to design the orthogonal array.

$>$ The level for the input parameters selected are IP, Infeed (If) and RPM as shown in Table 3 and Table 4.

$>$ L27 orthogonal array of full factorial DOE design have been used.

Table 3 Control parameters

\begin{tabular}{llllll}
\hline Sr. No. & Machine parameter & Unit & \multicolumn{2}{c}{ Level } \\
\cline { 4 - 6 } & & & $\mathbf{1}$ & $\mathbf{2}$ & $\mathbf{3}$ \\
\hline A & IP & Amp & 1 & 2 & 3 \\
B & RPM & RPM & 20 & 40 & 60 \\
C & If & $\mu \mathrm{m}$ & 30 & 60 & 90 \\
\hline
\end{tabular}

Table 4 Coded form of control parameters

\begin{tabular}{llllllllll}
\hline Factor & Name & Type & Sub type & Mini mum & Maxi mum & Coded & Values & Mean & Std. Dev. \\
\hline A & IP & & & 1 & 3 & $-1=1$ & $1=3$ & 2 & 0.816497 \\
B & RPM & Numeric & Continuous & 20 & 60 & $-1=20$ & $1=60$ & 40 & 16.32993 \\
C & If & & & 30 & 90 & $-1=30$ & $1=90$ & 60 & 24.4949 \\
\hline
\end{tabular}

\subsection{Specimen detail}

Total 27 experiments have been conducted by turning on round bar $3 \mathrm{~mm}$ diameter and $30 \mathrm{~mm}$ length machining up to $1 \mathrm{~mm}$ diameter and $10 \mathrm{~mm}$ length of GCr15 material.

\section{Analysis and results}

\subsection{Experimental table}

Experiment results shown in Table 5.

\subsection{Regression analysis}

$>$ Using design expert software, the regression equation was determined and the plot of actual predictive value was made.

> The regression formula was found using the design expert software and the regression equation is given below:
Final equation in terms of actual factors

$M R R=-0.71481+(0.73333 \times \mathrm{Ip})+(5.55556 \mathrm{E}-003 \times \mathrm{RPM})$

$+(0.038519 \times$ Infeed $)+(5.83333 \mathrm{E}-003 \times \mathrm{Ip} \times \mathrm{RPM})$

$+(8.33333 \mathrm{E}-004 \times \mathrm{Ip} \times$ Infeed $)+(1.11111 \mathrm{E}-004 \times \mathrm{RPM} \times$ Infeed $)$

$-\left(0.10556 \times \mathrm{Ip}^{2}\right)-\left(5.55556 \mathrm{E}-005 \times \mathrm{RPM}^{2}\right)-\left(2.28395 \mathrm{E}-004 \times \mathrm{Infeed}^{2}\right)$

The R-Sq $\left(\mathrm{R}^{2}\right)$ esteem shows that the indicators clarify $98.18 \%$ of the change in MRR.

$>$ The R-Sq (adj) (balanced $\mathrm{R}^{2}$ ) is $97.22 \%$, which represents the quantity of indicators in the model. The two qualities demonstrate that the model fits the information well as shown in Figure 6.

Table 5 L27 orthogonal array of experiments with results

\begin{tabular}{llllll}
\hline Std & Run & A: IP & B: RPM & C: Infeed & MRR \\
\hline 10 & 1 & 1 & 20 & 60 & 1.8 \\
21 & 2 & 3 & 20 & 90 & 3.1 \\
8 & 3 & 2 & 60 & 30 & 2.3 \\
3 & 4 & 3 & 20 & 30 & 2.1 \\
24 & 5 & 3 & 40 & 90 & 3.5 \\
13 & 6 & 1 & 40 & 60 & 2 \\
\hline
\end{tabular}


Harshadkumar Patel and Dhaval M. Patel.

\begin{tabular}{|c|c|c|c|c|c|}
\hline Std & Run & A: IP & B: RPM & C: Infeed & MRR \\
\hline 20 & 7 & 2 & 20 & 90 & 2.4 \\
\hline 17 & 8 & 2 & 60 & 60 & 3.3 \\
\hline 27 & 9 & 3 & 60 & 90 & 4.2 \\
\hline 15 & 10 & 3 & 40 & 60 & 3.2 \\
\hline 18 & 11 & 3 & 60 & 60 & 3.7 \\
\hline 16 & 12 & 1 & 60 & 60 & 2.3 \\
\hline 9 & 13 & 3 & 60 & 30 & 2.9 \\
\hline 14 & 14 & 2 & 40 & 60 & 2.9 \\
\hline 4 & 15 & 1 & 40 & 30 & 1.4 \\
\hline 6 & 16 & 3 & 40 & 30 & 2.6 \\
\hline 2 & 17 & 2 & 20 & 30 & 1.6 \\
\hline 12 & 18 & 3 & 20 & 60 & 2.8 \\
\hline 19 & 19 & 1 & 20 & 90 & 2.2 \\
\hline 7 & 20 & 1 & 60 & 30 & 1.6 \\
\hline 5 & 21 & 2 & 40 & 30 & 2.1 \\
\hline 22 & 22 & 1 & 40 & 90 & 2.2 \\
\hline 23 & 23 & 2 & 40 & 90 & 3.3 \\
\hline 25 & 24 & 1 & 60 & 90 & 2.7 \\
\hline 1 & 25 & 1 & 20 & 30 & 1.2 \\
\hline 26 & 26 & 2 & 60 & 90 & 3.5 \\
\hline 11 & 27 & 2 & 20 & 60 & 2.3 \\
\hline
\end{tabular}

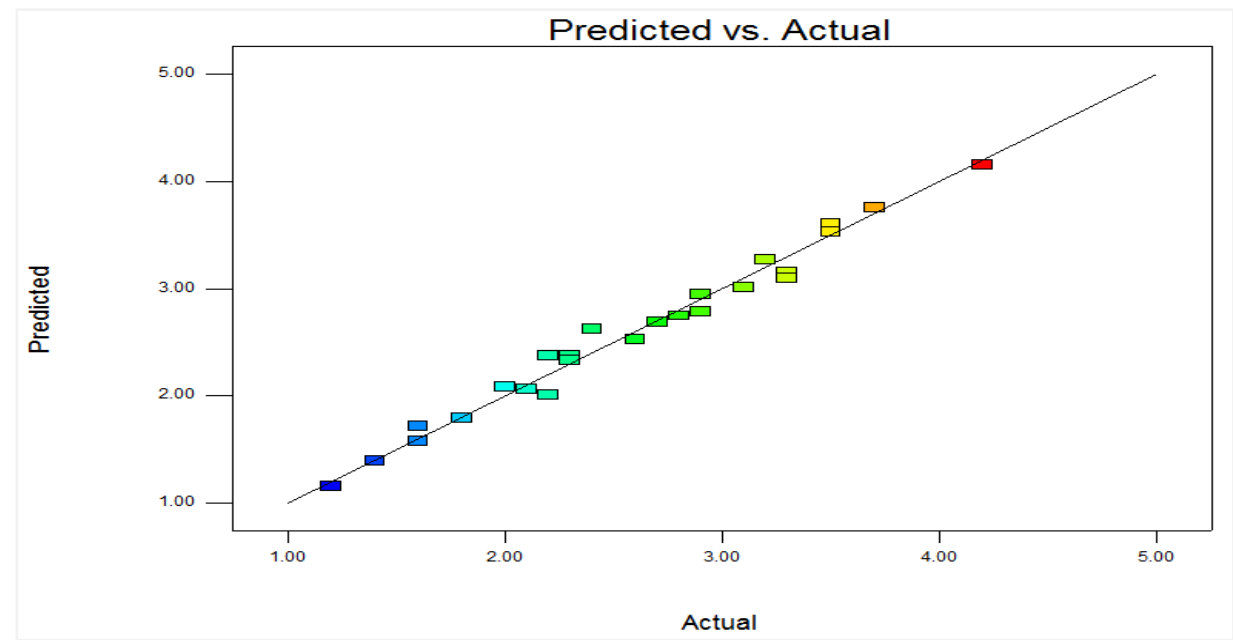

Figure 6 Actual vs. predicted value graph

\subsection{Analysis of variance (ANOVA)}

ANOVA shows the parameter effect in percentage form as shown in Table 6.

The resolution of the factorial design permits us to estimate all the main effects and factor interactions. Factual programming was executed to plan the tests and examine the exploratory discoveries.
Investigation of fluctuation (ANOVA) has been regularly tried, since it covers the deficiency of graphical evaluation.

All three parameters are significant and most effected parameter in IP (44.06\%) and RPM (18.86\%), and If (33.29\%). Residual is found very less that is $1.82 \%$.

Table 6 ANOVA results of experiments

\begin{tabular}{llll}
\hline Source & Sum of squares & Df & Percentage \\
\hline Model & 14.43528 & 9 & - \\
A-Ip & 6.360556 & 1 & 44.06 \\
B-RPM & 2.722222 & 1 & 18.86 \\
C-Infeed & 4.805 & 1 & 33.29 \\
AB & 0.163333 & 1 & 1.13 \\
\hline
\end{tabular}


International Journal of Advanced Technology and Engineering Exploration, Vol 6(53)

\begin{tabular}{llll}
\hline Source & Sum of squares & Df & Percentage \\
\hline $\mathrm{AC}$ & 0.0075 & 1 & 0.05 \\
$\mathrm{BC}$ & 0.053333 & 1 & 0.37 \\
$\mathrm{~A}^{\wedge} 2$ & 0.066852 & 1 & 0.46 \\
$\mathrm{~B}^{\wedge} 2$ & 0.002963 & 1 & 0.02 \\
$\mathrm{C}^{\wedge} 2$ & 0.253519 & 1 & 1.76 \\
Residual & 0.267685 & 17 & 1.82 \\
Cor Total & 14.70296 & 26 & 100 \\
\hline
\end{tabular}

\subsection{MRR results}

Figure 7 demonstrates that IP, RPM and If have the huge impact on MRR. What's more, the IP, RPM and If have direct extent of MRR change; that is, by expanding IP, RPM and If, MRR increments
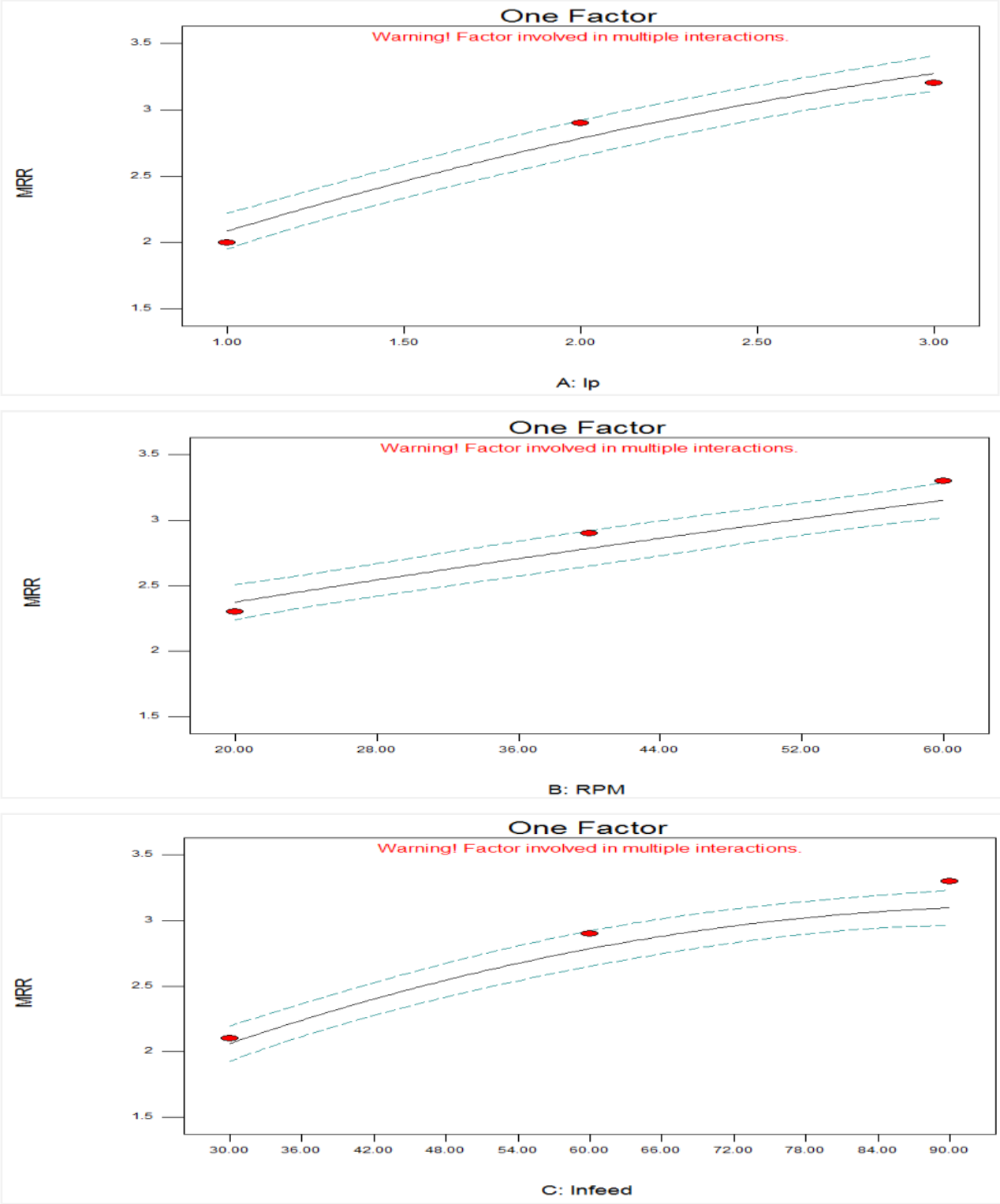

89 

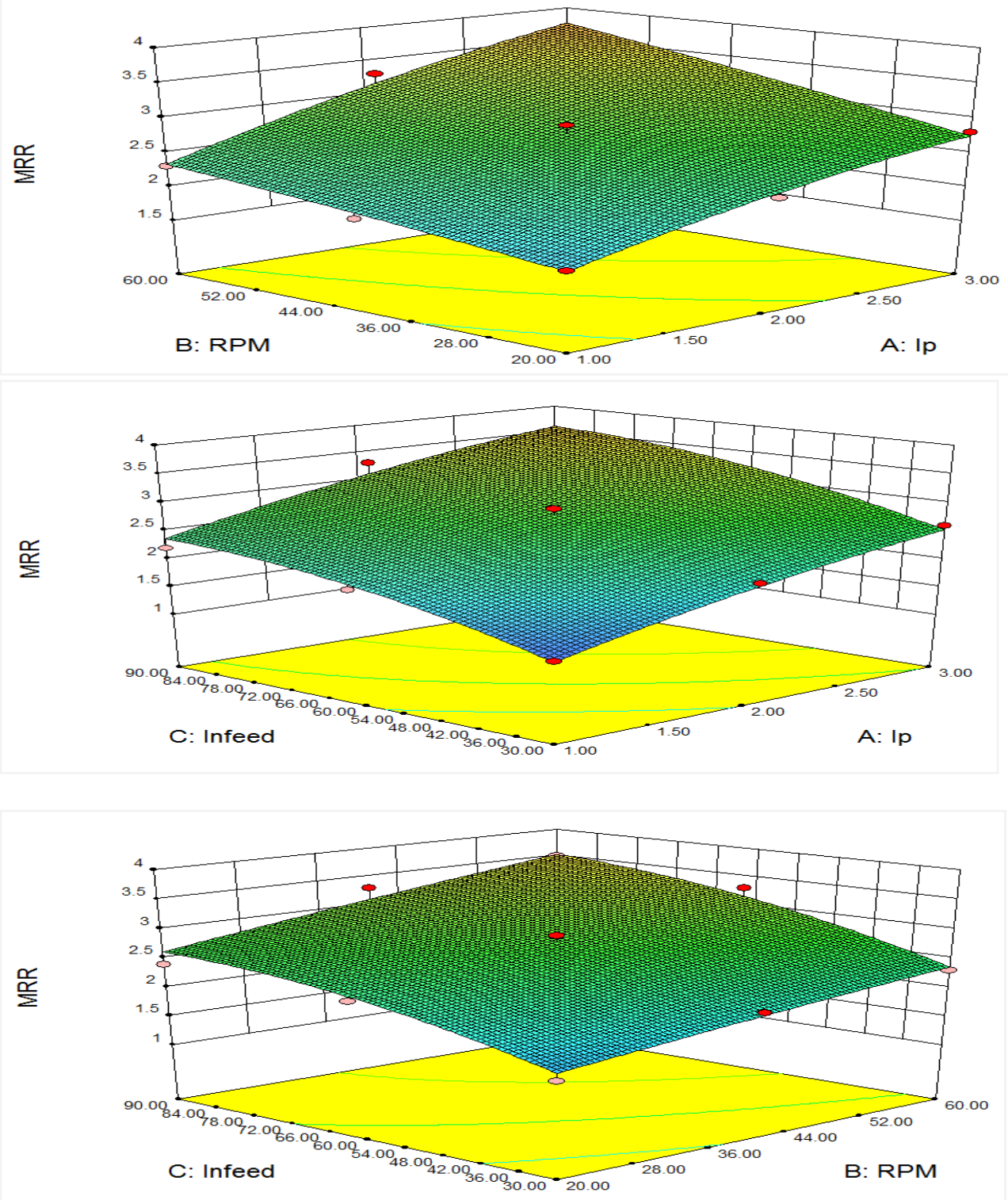

Figure 7 Plots of individual factor effects and interaction effects of changes of MRR

\section{Conclusion}

Material to make exact complex formed cylindrical shaped parts in both large scale and miniaturized scale level by applying a rotational axle on a typical wire EDM machine. So as to explore the ideal thickness of layers in the discretization procedure, a solitary factor try was directed to examine the connection between spiral if and MRR. The consequences of trial demonstrate that the greatest estimation of MRR can accomplish $4.2 \mathrm{~mm}^{3} / \mathrm{min}$ when the spiral If was $90 \mu \mathrm{m}$.
This examination presents an investigation of different procedure parameters and reached following determinations from the trial think about:

$>$ Procedure parameters influence distinctive reaction in various ways. Thus, need to set a parameter dependent on prerequisite.

If IP, SR and If value increase then the value of MRR also increase.

IP parameter is the most significant factor. 
Acknowledgment

The authors acknowledge the Smt. S. R. Patel Engineering College, Unjha (Grant No SRPEC/Project/2017-18//01) for their financial support.

\section{Conflicts of interest}

The authors have no conflicts of interest to declare.

\section{References}

[1] Joshi A, Samant SS, Mer KKS. Modelling surface finish in WEDM using RSM. International Journal on Theoretical and Applied Research in Mechanical Engineering. 2013; 2(4): 74-8.

[2] Qu J, Shih AJ, Scattergood RO. Development of the cylindrical wire electrical discharge machining process, part 1: concept, design, and material removal rate. Journal of Manufacturing science and engineering. 2002; 124(3):702-7.

[3] Qu J, Shih AJ, Scattergood RO. Development of the cylindrical wire electrical discharge machining process, part 2: surface integrity and roundness. Journal of Manufacturing Science and Engineering. 2002; 124(3):708-14.

[4] Balamurali D, Manigandan K, Sridhar V. Analysis of the effects of machining parameters on wire electrical discharge turning of stainless steel. Journal of Advanced Engineering Research. 2015; 2(1):34-41.

[5] Baki N, Reddy AC, Rao TB. Selection of optimal process parameters in wire-electrical discharge turning while machining TI-6AL-4V ALLOY. In international conference on advanced materials and manufacturing technologies 2014:147-57.

[6] Haddad MJ, Tajik M, Tehrani AF, Mohammadi A, Hadi M. An experimental investigation of cylindrical wire electrical discharge turning process using Taguchi approach. International Journal of Material Forming. 2009; 2(3):167-79.

[7] Mohammadi A, Tehrani AF, Emanian E, Karimi D. A new approach to surface roughness and roundness improvement in wire electrical discharge turning based on statistical analyses. The International Journal of Advanced Manufacturing Technology. 2008; 39(12):64-73.

[8] Haddad MJ, Tehrani AF. Material removal rate (MRR) study in the cylindrical wire electrical discharge turning process. Journal of Materials Processing Technology. 2008; 199(1-3):369-78.

[9] Zhu Y, Liang T, Gu L, Zhao W. Machining of micro rotational parts with wire EDM machine. Procedia Manufacturing. 2016; 5:849-56.

[10] Mohammadi A, Tehrani AF, Abdullah A. Introducing a new technique in wire electrical discharge turning and evaluating ultrasonic vibration on material removal rate. Procedia CIRP. 2013; 6:583-8.

[11] Janardhan V, Samuel GL. Pulse train data analysis to investigate the effect of machining parameters on the performance of wire electro discharge turning (WEDT) process. International Journal of Machine Tools and Manufacture. 2010; 50(9):775-88.
[12] Gong Y, Sun Y, Wen X, Wang C, Gao Q. Experimental study on surface integrity of Ti-6Al-4V machined by LS-WEDM. The International Journal of Advanced Manufacturing Technology. 2017; 88(14):197-207.

[13] Chen X, Wang Z, Wang Y, Chi G, Guo C. Micro reciprocated wire-EDM of micro-rotating structure combined multi-cutting strategy. The International Journal of Advanced Manufacturing Technology. 2018; 97(5-8):2703-14.

[14] Krishnan SA, Samuel GL. Multi-objective optimization of material removal rate and surface roughness in wire electrical discharge turning. The International Journal of Advanced Manufacturing Technology. 2013; 67(9-12):2021-32.

[15] Mohammadi A, Fadaei Tehrani A, Abdullah A, Danesh M. Investigation of ultrasonic-assisted wire electrical discharge turning based on single discharge analysis. Proceedings of the Institution of Mechanical Engineers, Part B: Journal of Engineering Manufacture. 2014; 228(11):1372-80.

[16] Parthiban M, Krishnaraj V, Sindhumathi R, Valentinciiĉ J. Investigation on manufacturing of microtools made of tungsten carbide using wire electric discharge grinding (WEDG). Journal of the Brazilian Society of Mechanical Sciences and Engineering. 2017; 39(9):3571-80.

[17] Zhu Y, Liang T, Gu L, Zhao W. Precision machining of high aspect-ratio rotational part with wire electro discharge machining. Journal of Mechanical Science and Technology. 2017; 31(3):1391-9.

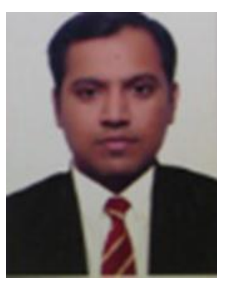

Mr. Harshadkumar Chaturbhai Patel is currently $\mathrm{PhD}$ Research Scholar from Ganpat University, Gujarat. He is Assistant Professor in Mechanical Department in Smt. S. R. Patel Engineering College, Unjha (Gujarat), India. His research areas are Unconventional

Machining,

Automation and Robotics.

Email: patelharshad25@gmail.com

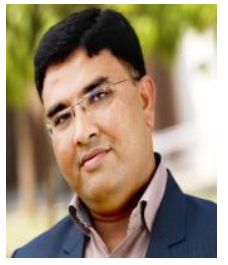

Dr. Dhaval M. Patel, Professor, Mechanical Engineering Department, Vishwakarma Government Engineering College, Gujarat (INDIA) having more than 12 years of research experience in the field of Unconventional Machining, Integrated Manufacturing, Laser Processing of Materials and Micro Manufacturing and also associated with more than 76 publications. 